S. Shilin, PhD,

O. Shablykina, PhD,

shablykina@ukr.net,

Taras Shevchenko National University of Kyiv, Kyiv, Ukraine

O. Shablykin, PhD,

V. P. Kukhar Institute of Bioorganic Chemistry and Petrochemistry of the NAS of Ukraine, Kyiv, Ukraine

V. Khilya, Dr. Sci., Corresponding Member of the NAS of Ukraine,

Z. Nagorna, stud.,

Taras Shevchenko National University of Kyiv, Kyiv, Ukraine

\title{
CERTAIN CASES OF O-ALKOXYCINNAMIC ACIDS CREATION FROM COUMARINS IN O-ALKYLATION CONDITION
}

A number of new derivatives of o-alkoxy cinnamic acids were obtained from various coumarins by opening the lactone fragment and 0 -alkylation of the endocyclic Oxygen atom.

The $\alpha$-hetaryl- $\beta$-(2-alkoxy-5-chlorophenyl)cinnamic acids were obtained from 3-(benzothiazol-2-yl)-6-chlorocoumarin and 3-(benzimidazol-2-yl)-6chlorocoumarin by treatment with diluted alkali followed by p-methylbenzyl chloride or dimethyl sulfate addition, respectively.

A similar reaction stages (opening in aqueous alkali and alkylation of the phenolate anion) was applied to the synthetic analogues of psoralen 5-methylfuro[3,2-g]coumarins with various substituents in the furan fragment. Thus it was possible to obtain a number of 3- and 4-substituted 3-(6alkoxybenzofuran-5-yl)but-2-enoic acids. But in this case, the conversion of the starting furo[3,2-g]coumarins to cinnamic acid derivatives was not complete even after long time of reaction with a big excess of an alkylation agent. Therefore, the necessary step is the separation of the target acid from unreacted coumarin by dissolving the product in a saturated $\mathrm{NaHCO}_{3}$ solution. The insoluble part is a practically pure starting material, which can be recycled in the reaction; so the total yield of the product would be increased. To demonstrate the synthetic abilities of 3-(6-alkoxybenzofuran5-yl)but-2-enoic acids these compounds were used in synthesis of amides with pharmacophore fragments: a phenethylamine derivative with an additional sulfamide group and a $\beta$-alanine derivative.

The experiments showed that the 3-azolylcoumarins and furo[3,2-g]coumarins coumarin cycle's opening occurs only in aqueous alkali, and when alkylated in an organic solvent in the presence of $\mathrm{K}_{2} \mathrm{CO}_{3}$, the lactone fragment remains unchanged. The 7-hydroxy-6-(isocoumarin-3-yl)-4methylcoumarin cycle turned out to be more labile. The result of alkylation of this compound with ethyl acetate of chloroacetic acid in the presence of $\mathrm{K}_{2} \mathrm{CO}_{3}$ depended on the nature of the aprotic solvent and the temperature of reaction. So, when this reaction was carried out in boiling acetone, only the free hydroxyl group at position 7 of coumarin was alkylated. But when the initial coumarin was heated at $100{ }^{\circ} \mathrm{C}$ with an excess of an alkylating agent in DMSO, simultaneous alkylation of both the free 7-OH group and the endocyclic Oxygen atom occurred.

Keywords: coumarin, alkylation, o-alkoxycinnamic acid.

УДК 678.621.315.772.93

DOI: https://doi.org/10.17721/1728-2209.2019.1(56).7

Н. Давиденко, д-р физ.-мат. наук, И. Давиденко, д-р физ.-мат. наук, Киевский национальный университет имени Тараса Шевченко, Киев, Украина

В. Кравченко, д-р хим. наук, Институт физико-органической химии и углехимии им. Л. М. Литвиненко НАН Украины, Киев, Украина

Е. Мокринская, канд. хим. наук, mokrinskaya@ukr.net, В. Павлов, вед. инж.,

С. Студзинский, канд. хим. наук, В. Тарасенко, инж. 1 кат.,

Л. Тонкопиева, канд. хим. наук,

Киевский национальный университет имени Тараса Шевченко, Киев, Украина

\section{ВЛИЯНИЕ ПРИРОДЫ ЗАМЕСТИТЕЛЯ В АЗОБЕНЗОЛЬНЫХ ХРОМОФОРАХ НА ДИФРАКЦИОННУЮ ЭФФЕКТИВНОСТЬ ПОЛЯРИЗАЦИОННЫХ ГОЛОГРАММ}

На основе пленок сополимера стирола с нонилметакрилатом и добавками азобензольных красителей с различными акцепторными заместителями созданы регистрирующие среды для поляризационной голографии и исследованы их фотоэлектрофизические и информационные свойства. Обнаружено, что при изменении взаимной ориентации записываюцих лучей от ортогональной к параллельной дифракционная эффективность голограмм увеличивается в случае использования азокрасителя с заместители в орто- и пара-положении по отношению к азогруппе. Обнаруженный эффект зависимости дифракционной эффективности от строения хромофоров связывается с углублением цвета красителя.

Ключевые слова: азобензольные красители, электроноакцепторные заместители, поляризационная голография, регистрирующие среды, дифракционная эффективность.

Введение. Пленки полимерных композитов (ППК) с добавками азокрасителей или содержащие химически связанные с основной полимерной цепью азобензольные группы проявляют фотоактивные свойства [1-3] и их можно использовать для создания электрооптических модуляторов [4] света и регистрирующих сред (РС) для поляризационной голографиии [5-7]. Под действием линейно поляризованного света в этих пленках появляется фотоиндуцированная оптическая анизотропия (ФОА), которая вызвана процессами транс-цис-изомеризации азобензольных групп. Этот эффрект позволяет использовать рассматриваемые композиты в качестве РС для поляризационной голографиии. Дифракционная эффективность (ДЭ) получаемых поляризационных голограмм существенно зависит от состава РС. Большое значение имеет количество введенного в матрицу азокрасителя, его структура и интенсивность окраски. В данной работе рассмотрено влияние различных акцепторных заместителей в азокрасителе на ДЭ поляризационных голограмм, регистрируемых в РС, содержащих такие красители.

( С Давиденко Н., Давиденко И., Кравченко В., Мокринская Е., Павлов В., Студзинский С., Тарасенко В., Тонкопиева Л., 2019 дований нами синтезированы азокрасители следующего строения:<smiles>Cc1cc(N=Nc2ccc([N+](=O)[O-])cc2)ccc1O</smiles><smiles>O=[N+]([O-])c1ccc(/N=N/c2ccc(O)cc2)c(Br)c1</smiles>

4-(2-бром-4- нитрофенилазо)фенол (3)
Материалы и методика исследований. Для иссле- 
Состав и структуру синтезированных сополимеров идентифицировали методами элементного анализа, ${ }^{1} \mathrm{H}$ ЯМР- и УФ-спектроскопии. Элементный анализ полученных соединений осуществляли на CHNOS-элементном анализаторе Elementar Gmbh "Vario Micro Cube". ${ }^{1} \mathrm{H}$ ЯМР-спектры полученных веществ снимали на ${ }^{1} \mathrm{H}$ ЯМРспектрометре Varian "Mercury-400" в ДМСО-d6 с тетраметилсиланом в качестве внутреннего стандарта.

Для исследований готовили образцы РС со свободной поверхностью ППК, а также образцы сэндвич-структуры соответствующих ППК (стеклянная подложка прозрачный электропроводящий слой $\mathrm{SnO}_{2}: \ln _{2} \mathrm{O}_{3}$ (ITO) ППК - Ag-электрод) путем полива раствора сополимера с $10 \%$ мас. (по отношению к массе полимера) азокрасителя в дихлорэтане на стеклянные подложки, с последующей сушкой в течение 48 часов в термошкафу при температуре $80^{\circ} \mathrm{C}$. Для нанесения серебряного электрода в образцах сэндвич-структуры использовали токопроводящую пасту фирмы Electrolube. Толщина исследуемых ППК, измеренная с помощью интерференционного микроскопа МИИ-4, составляла 1,8-2,0 мкм.

Для образцов РС со свободной поверхностью ППК регистрировали спектры оптического поглощения в диапазоне длин волн $\lambda=200-800$ нм при помощи спектрофотометра Varian Cary-50 UV-VIS.

Эти же образцы PC использовали и для записи голограмм плоского волнового фронта. Использовали излучение $\lambda_{1}=532 \mathrm{Hм}$ твердотельного лазера с диодной накачкой и удвоением частоты при соотношении интенсивности света в объектном $\left(l_{1}\right)$ и опорном $\left(l_{2}\right)$ лучах $1: 1$; пространственная частота при этом составляла $300 \mathrm{~mm}^{-1}$. Интенсивность света $l_{1}+l_{2}$, падающего на РС, составляла $5 \cdot 10^{3} \mathrm{BT} / \mathrm{M}^{2}$. Запись голограмм проводили для параллельной $\left(\boldsymbol{e}_{1} \| \boldsymbol{e}_{2}\right)$ и перпендикулярной $\left(\boldsymbol{e}_{1} \perp \mathbf{e}_{2}\right)$ ориентации электрических векторов падающих объектной $\left(\mathbf{e}_{1}\right)$ и опорной $\left(\mathbf{e}_{2}\right)$ световой волны. Величину дифракционной эффективности ( $)$ голограммы определяли по общепринятой методике [8] как отношение интенсивности света в 1-м порядке дифракции к интенсивности опорного луча $I_{2}$ (он же восстанавливающий луч в процессе считывания) для параллельной $\left(\boldsymbol{e}_{1} \| \boldsymbol{e}_{2}\right)$ и перпендикулярной $\left(\boldsymbol{e}_{1} \perp \mathbf{e}_{2}\right)$ ориентации электрических векторов записывающих световых волн (соответственно как $\eta_{\|}$и $\eta_{\perp}$ ). Измеряли зависимости $\eta_{\|}(t)$ и $\eta_{\perp}(t)$ от времени $(t)$ после начала и завершения экспонирования голограммы. Каждое новое измерение проводили на новом участке РС для исключения влияния предыдущего эксперимента (памяти о записи голограммы). Результаты измерений усредняли по трем образцам идентичных РС.

В образцах сэндвич-структуры измеряли: плотность темнового тока $\left(\mathrm{j}_{\mathrm{d}}\right)$ и фототока (jрн) в зависимости от величины и полярности электрического напряжения (U) (соответственно от величины напряженности $E=U / L$ электрического поля и направления силовых линий этого поля в образцах), приложенного к электрическим контактам [9], а также диэлектрические характеристики полученных ППК - величину тангенса угла диэлектрических потерь (tgס) и электрической емкости (С) для частоты $f=200-10^{3}$ Гц синусоидального переменного электрического напряжения с действующим значением 10 В без облучения и при облучении светом [10-11]. Из последних измерений рассчитывали величину $\Delta \operatorname{tg} \delta_{\mathrm{PH}}=$ $\left(\operatorname{tg} \delta_{\mathrm{PH}}-\operatorname{tg} \delta_{0}\right) / \operatorname{tg} \delta_{0}$ и $\Delta \mathrm{C}_{\mathrm{PH}}=\left(\mathrm{C}_{\mathrm{PH}}-\mathrm{C}_{0}\right) / \mathrm{C}_{0}$, где $\operatorname{tg} \delta_{0}, \mathrm{C}_{0}$ и $\operatorname{tg} \delta_{\mathrm{PH}}, \mathrm{C}_{\mathrm{PH}}$ - соответственно значения тангенса угла диэлектрических потерь и емкости до и после включе- ния света облучения. В качестве источников света облучения для измерений јрн и диэлектрических исследований использовали синий полупроводниковый светодиод с максимумом излучения 420 нм, I = 40 Bт/ $\mathrm{M}^{2}$ ). Освещение образцов производили со стороны ITOэлектрода. Изменение јрн в зависимости от времени (t) облучения и после выключения света регистрировали с помощью запоминающего осциллографа и цифрового вольтметра. Все измерения проведены при комнатной температуре $20^{\circ} \mathrm{C}$.

Результаты исследований и их обсуждение. На рис. 1 представлены нормированные спектры оптической плотности ППК с красителями 1-3. В видимой области поглощение этих ПП определяется длинноволновым краем поглощения азохромофоров. При переходе от ППК с добавками красителя 1 к ППК с добавками красителя 3 наблюдается батохромный сдвиг поглощения соответствующих полимерных композитов. Поскольку в пленках (1-3) концентрация азохромофоров одинакова, батохромный сдвиг в спектрах связан с понижением энергии возбуждения хромофоров, что обусловлено наличием атомов галогена в структуре азохромофора 2 и 3. Углубление окраски достигается вследствие введения в молекулу ауксохромных электронодонорных и электроноакцепторных заместителей, положение заместителя по отношению к азогруппе также сильно влияет на ауксохромный эфрфект. Особенно эфффективно сопряжение в пара-положении благодаря увеличению длины сопряженной цепи и отсутствию стерических воздействий, приводящих к некопланарности системы и, как следствие, к нарушению сопряжения с ней [12]. При этом происходит увеличение протяженности сопряженной п-электронной системы и увеличение ее поляризуемости. В результате возбуждение азохромофора становится возможным при поглощении квантов света меньшей энергии, что и обусловливает батохромный сдвиг спектра поглощения красителя.

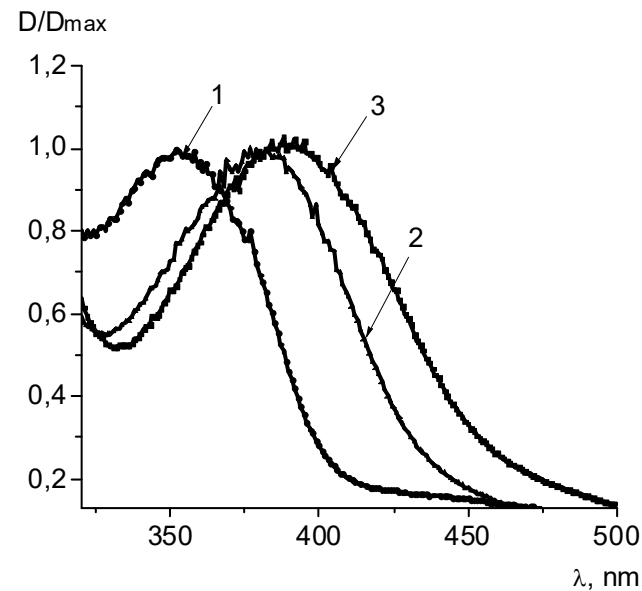

Рис. 1. Нормированные спектры поглощения PC с азокрасителем 1 (кривая 1), 2 (кривая 2), 3 (кривая 3)

В исследуемых РС с ППК 1-3 нами зарегистрированы голограммы плоского волнового фронта как для случая $\mathbf{e}_{1} \| \mathbf{e}_{2}$, так и для случая $\mathbf{e}_{1} \perp \mathbf{e}_{2}$. На рис. 2 представлены графики зависимости $\eta(t)$ в процессе записи голограммы и после выключения объектного луча. В исследованных образцах РС с ППК 1-3 кинетика нарастания и особенно релаксации $\eta(t)$ носит быстрый характер. 

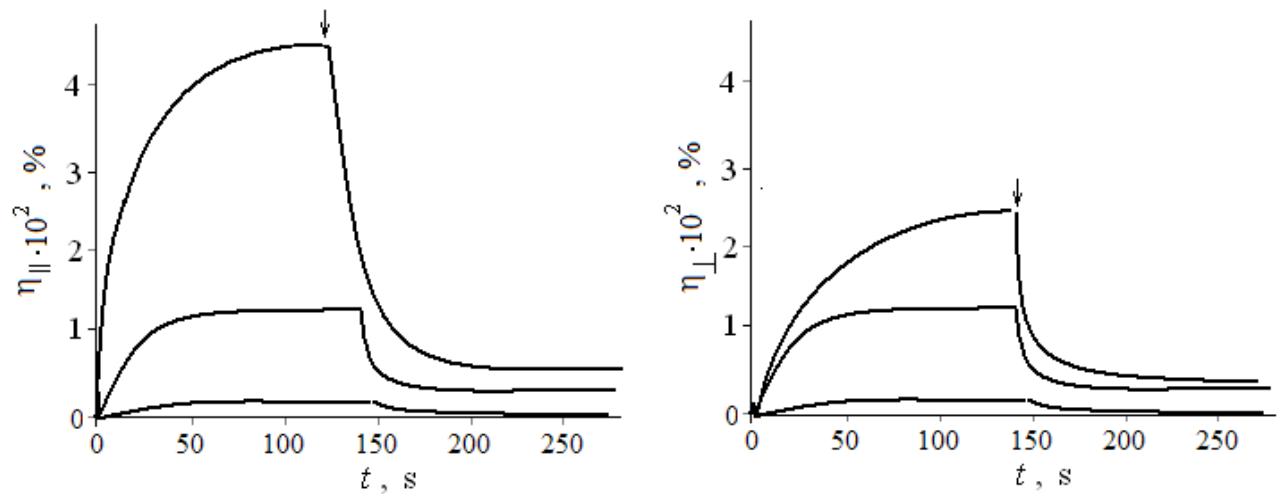

Рис. 2. Графики зависимости $\eta_{\|}$и $\eta_{\perp}$ после начала $(t=0)$ записи голограммы и выключения объектного луча в момент времени $t=2$ мин в образцах РС с ПП 1-3.

Момент выключения объектного луча отмечен вертикальной стрелкой, направленной вниз

Под действием линейно поляризованного света из области поглощения азобензольных хромофоров происходит транс-цис-изомеризация соответствующих азофррагментов. Считается $[5,13,14]$, что именно перестройка полимерной матрицы ответственна за длительное хранение записи голограмм. Азобензольные группы, участвующие в фотоизомеризации при экспонировании голограммы, ориентируются в соответствующих направлениях и появляются дополнительные деформирующие силы, действующие на полимерную матрицу, что приводит к формированию геометрического рельефра поверхности ППК в РС. Кроме того, при экспонировании поляризованным светом происходит перераспределение концентраций соответствующих изомерных форм азохромофроров в объеме ППК в различных направлениях, что также приводит к модуляции оптических свойств системы. На перераспределение концентраций транс-цисизомеров азокрасителей в объеме РС указывают также результаты фотодиэлектрических исследований.

Во всех исследованных ППК величина относительного изменения $\Delta \operatorname{tg} \delta_{\mathrm{PH}}<0$, т.е. величина тангенса угла диэлектрических потерь tgס, уменьшается при облучении (величина электрической емкости также незначительно уменьшается), что может свидетельствовать об уменьшении величины дипольного момента азохромофроров при облучении, либо также об уменьшении подвижности или концентрации свободных подвижных носителей тока в системе $[10-11,15]$. Результаты проведенных нами дополнительных исследований темновой электро-, а также фотопроводимости созданных ППК (в образцах сэндвич-структуры) свидетельствуют о том, что вплоть до напряженностей порядка $\mathrm{E} \sim 3-4 \cdot 10^{7}$ В/м внешнего электрического поля (что в 6-7 раз превосходит величину напряженности электрических полей, используемых нами в фотодиэлектрических исследованиях) соответствующие величины фототоков во всех исследованных ППК не превосходят заметно уровня шумов, что говорит о практическом отсутствии влияния вклада процессов фотопроводимости за счет свободных фотогенерированных носителей заряда в объеме ППК на величину фотодиэлектрического эфффекта в исследованных ППК. Следовательно, отрицательный знак фотодиэлектрического эфффекта в исследуемых ППК следует приписать уменьшению величины дипольного момента молекул азокрасителей при облучении пленок, индуцирующее процессы E-Z изомеризации азохромофоров. Такой вывод согласуется с тем фактом, что для используемых в работе азокрасителей величина дипольного момента для цис-изомера (Z-срормы) меньше, чем для транс-формы (Е-срормы)
[13-16]. В таблице 1 приведены величины $\Delta \operatorname{tg} \delta_{p н}$ для ППК с красителями 1-3 на частоте 800 Гц.

таблица 1

Величины $\Delta \operatorname{tg} \delta_{\text {Pн }}$ В образцах сэндвич-структуры ППК с добавками красителей 1-3, измеренные на частоте $f=800$ Гц при использовании в качестве источника излучения синего полупроводникового светодиода $\left(\lambda_{\text {irr }} \sim 420 \mathrm{HM}, \mathrm{I}=40 \mathrm{BT} / \mathrm{M}^{2}\right)$

\begin{tabular}{|c|c|}
\hline Краситель & $\Delta \mathbf{t g}_{\mathbf{P H}}$ \\
\hline 1 & 0,210 \\
\hline 2 & 0,170 \\
\hline 3 & 0,242 \\
\hline
\end{tabular}

Выводы. Наибольшая дифракционная эфффективность при записи голограмм плоского волнового фронта в созданных полимерных композитах наблюдается в РС с красителем 3, содержащим заместители в орто- и параположении по отношению к азогруппе, что объясняется увеличением длины $\pi$-сопряжения системы и усилением поверхностного рельефа и величины п при углублении окраски. Можно считать, что при записи под действием линейно поляризованного света из области поглощения красителей происходит транс-цис-изомеризация азофрагментов и их фотоориентация, а также изменяется соотношение концентраций соответствующих изомерных форм последних, а именно - возрастает концентрация цис-изомерной формы, характеризующейся меньшими величинами дипольного момента. Полученные пленочные структуры могут быть использованы в качестве РС для поляризационной голографии.

Список викорыстаных джерел

1. Naydenova I. (Ed.). Holograms - Recording materials and applications. Rijeka, Intech. 2011. 396 p.

2. Yesodha S., Pillai C., Tsutsumi N. Prog. Polym. Sci. 2004. 29. 45-74.

3. Che P., He Ya., Wang X. Macromolecules. 2005. 38. 8657-8663.

4. Davidenko N. A., Davidenko I. I., Savchenko I. A., Popenaka A. N. Baath L. B. J. Appl. Phys. 2008. 103. 9. 094223-094227.

5. Nikolova L., Ramanujam P.S. Polarization Holography. Cambridge : Cambridge University Press, 2009. 256 p.

6. Yoshimura T. Thin-Film Organic Photonics: Molecular Layer Deposition and Applications. Boca Raton ; London ; New York : CRC Press, 2011. 370 p.

7. Davidenko N. A., Davidenko I. I., Pavlov V. A., Popenaka A. N., Savchenko I. A., Shumeluk A. N. Theor. Exp. Chem. 2009. 45. 54-57.

8 Collier R. J., Burckhart C. B., Lin L. H. Optical holography. N.Y. and London : Academic Press, 1973. 624 p.

9. Davidenko N. A, Studzinsky S. L., Tonkopieva L. S., Ishchenko A. A., Spitsina N. G., Lobach A. S. Theor. Exp. Chem. 2007. 43. 6. 385-388.

10. Лущейкин Г. А. Методы исследования электрических свойств полимеров. М. : Химия, 1988. 160 с.

Luscheykin G. A. Research methods for the electrical properties of polymers. Moscow : Khimiia, 1988. 160 p.

11. Studzinsky S. L. Mol. Cryst. Liq. Cryst. 2014. 589. 183-194.

12. Голодников Г. В., Мандельштам Т. В. Практикум по органическому синтезу. Л. : Изд-во Ленинград. ун-та, 1976. 376 с.

Golodnikov G. V., Mandelstam T. V. Practical handbook of organic synthesis. Leningrad : Publishing House of Leningrad University, 1976. 376 p. 
13. Zhao Y., Tomiki I. Smart Light-Responsive Materials. AzobenzeneContaining Polymers and Liquid Crystals, Wiley-Interscience. 2009. 544 p.

14. Priimagi A., Shevchenko A. J. Polym. Sci. Pol. Phys. 2014. 52. 163-182.

15. Blythe T., Bloor D. Electrical Properties of Polymers. Second edition.

Cambridge : Cambridge University Press, 2005. 480 p.
16. Минкин В. И., Осипов О. А., Жданов Ю. А. Дипольные моменты в органической химии. Л. : Химия, 1968. 248 с.

Minkin V. I., Osipov O. A., Zhdanov Yu. A. Dipole moments in organic chemistry. Leningrad : Khimiia, 1968. 248 p.

М. Давиденко, д-р фіз.-мат. наук,

І. Давиденко, д-р фіз.-мат. наук,

Київський національний університет імені Тараса Шевченка, Київ, Україна

В. Кравченко, д-р хім. наук

Інститут фізико-органічної хімії і вуглехімії ім. Л. М. Литвиненка НАН України, Київ, Україна

О. Мокринська, канд. хім. наук,

mokrinskaya@ukr.net,

В. Павлов, провід. інж.,

С. Студзинський, канд. хім. наук,

В. Тарасенко, інж 1 кат.

Л. Тонкопіева, канд. хім. наук,

Київський національний університет імені Тараса Шевченка, Київ, Україна

\section{ВПЛИВ ПРИРОДИ ЗАМІСНИКА В АЗОБЕНЗОЛЬНИХ ХРОМОФОРАХ НА ДИФРАКЦІЙНУ ЕФЕКТИВНІСТЬ ПОЛЯРИЗАЦІЙНИХ ГОЛОГРАМ}

На основі плівок кополімеру стиролу з нонілметакрилатом і добавками азобензольних барвників з різними акцепторними замісниками створено реєструючі середовища для поляризаційної голографії та досліджено їхні фотоелектрофізічні та інформаційні властивості. Виявлено, що при зміні взаємної орієнтації записуючих променів від ортогональної до паралельної дифракційна ефективність голограм збільшується в разі використання азобарвника із замісниками в орто- $і$ пара-положенні щодо азогрупи. Виявлений ефект залежності дифракційної ефективності від будови хромофорів пов'язується із поглибленням кольору барвника.

Ключові слова: азобензольні барвники, електроноакцепторні замісники, поляризаційна голографія, реєструючі середовища, дифракційна ефективність.

M. Davidenko, Dr. Sci.

I. Davidenko, Dr. Sci.,

Taras Shevchenko National University of Kyiv, Kyiv, Ukraine

V. Kravchenko, Dr. Sci.,

L. M. Litvinenko Institute of Physical-Organic Chemistry and Coal Chemistry, NAS of Ukraine, Kyiv, Ukraine

O. Mokrinska, PhD,

mokrinskaya@ukr.net,

V. Pavlov, eng.,

S. Studzinsky, PhD,

V. Tarasenko, eng. 1 cat.,

Tonkopiyeva, PhD,

Taras Shevchenko National University of Kyiv, Kyiv, Ukraine

\section{THE EFFECT OF THE SUBSTITUENT NATURE IN THE AZOBENZENE CHROMOPHORES ON DIFFRACTION EFFICIENCY OF POLARIZATION HOLOGRAMS}

The films of polymeric composites containing monomers of azobenzene dyes or azobenzene lateral groups chemically bonded to the main polymer chain demonstrate photoactive properties, and can be used in electrooptical light modulators and in recording media (RM) for polarization holography. Photoinduced optical anisotropy (PIA) appears under influence of linearly polarized light caused by the processes of trans-cis-izomerization of the azobenzene groups. This process is determining for application of the considered materials as RM for polarization holography.

The films of polymeric polarization sensitive media based on a copolymer of styrene with nonyl methacrylate doped with azobenzene-type dyes with different electron-acceptor substituents are obtained in this work. In the films of copolymer the holograms of the plane wave front were registered for parallel and orthogonal orientations of polarization vectors of the object and reference light beams.

Their photoelectrophysical, in particular photodielectric, and information properties are investigated. It was established, that when the mutual orientation of the recording beams changes from the orthogonal to parallel orientation the diffraction efficiency of the holograms increases in the case of using azo dye with the maximum number of auxochromic substituents in the molecule. The effect of the diffraction efficiency dependence on the chromophores structure is connected with the deepening of dye color. The photo-induced optical anisotropy in the films appears due to a change of the concentration ratio of trans- and cis-isomers of azobenzene dye fragments. This conclusion is confirmed by the photodielectric measurements data, namely, by the negative sign of the photodielectric effect, observed experimentally in the investigated thin film structures. It was shown, that investigated compositions can be used as information media for polarization holography.

Keywords: azobenzene dyes, electron-acceptor substituents, polarization holography, recording media, diffraction efficiency.

УДК 541.64

DOI: https://doi.org/10.17721/1728-2209.2019.1(56).8

О. Харченко, канд. хім. наук, oksanakharchenko@ukr.net,

В. Смокал, канд. хім. наук,

О. Крупка, канд. хім. наук,

О. Колендо, д-р хім. наук,

Київський національний університет імені Тараса Шевченка, Київ, Україна

\section{ТЕРМОСТАБІЛІЗАЦІЯ ПОЛІСТИРОЛУ СТИРИЛХІНОЛІНВМІСНИМИ МЕТАКРИЛАТАМИ}

Методом динамічного термогравіметричного аналізу досліджено термодеструкцію зразків полістиролу, легованих новими стирилхінолінвмісними метакриловими мономерами. Установлено, що досліджені мономери при їх ковалентному введенні в полістирол є ефективними інеібіторами термодеструкції полістиролу на повітрі.

Ключові слова: стирилхінолінвмісні мономери, метакрилові мономери, полістирол, термостабілізація.

Вступ. Постійне розширення областей використання полімерів, підвищення вимог до їхніх експлуатаційних характеристик, економічності та екологічної чистоти ставить завдання ефективної стабілізації полімерних мате- ріалів [1]. Створення високоефективних внутрішньомолекулярних мономерів-стабілізаторів, які введено в полімерні ланцюги у невеликих кількостях під час синтезу основного полімеру - новий підхід в отриманні полімерних матеріалів, стійких до дії тепла, світла та інших факторів. 